\title{
Prevention of perinatal hepatitis B virus transmission in an obstetric/infant population
}

\author{
PAUl J PARKER, MD, MPH, THERESA W GYORKOS, PHD, JOSEPH S DYLEWSKI, MD, ARVIND K JOSHI, MD, \\ ELAINE D FRANCO, MD MPH
}

\begin{abstract}
PJ PARKer, TW Gyorkos, JS Dylewski, AK Josh, ED Franco. Prevention of perinatal hepatitis B virus transmission in an obstetric/infant population. Can J Infect Dis 1993;4(5):288-291.

Study Design: This retrospective study reviewed the screening practice and seroprevalence of hepatitis B surface antigen (HBsAg) among all mothers with live births at a teaching hospital in Montreal between November 1, 1990 and April 30, 1991. Resurts: Most women (94\%) were screened prenatally and 5.2\% postnatally. Screening status could not be determined for $0.8 \%$ of women. One-quarter of all postnatal screening results were available only at $48 \mathrm{~h}$ or more postdelivery. No infants born to women with postnatal screening or to women with unknown screening status were immunized expectantly. The maternal seroprevalence was $1.08 \%$ (95\% confidence interval from 0.6, 1.4). All 22 infants born to HBsAg-positive mothers had received hepatitis B immune globulin within $12 \mathrm{~h}$ of birth and the first dose of hepatitis B vaccine within $24 \mathrm{~h}$. Follow-up of infants revealed that only $50 \%$ had received the second and third doses according to the recommended protocol, with $83 \%$ completing the immunization series. Conclusion: These results indicate that a program of prenatal HBsAg screening and neonatal prophylaxis against hepatitis B can be successfully instituted in a high volume obstetric hospital, and that better monitoring of infants is required to ensure completion of vaccination.
\end{abstract}

Key Words: Hepatitis B, Immunization schedule, Perinatalogy, Prenatal care, Preventive health services

\section{Prévention de la transmission du virus de l'hépatite B périnatale dans une population obstétricale/nourrissons}

\begin{abstract}
MODÈLE DE L'ÉTUDE: Cette étude rétrospective a passé en revue les mesures de dépistage et la séroprévalence de l'antigène de surface de l'hépatite B (HBsAg) chez toutes les mères ayant donné naissance à des enfants vivants dans un centre hospitalier universitaire de Montréal entre le $1^{\mathrm{er}}$ novembre 1990 et le 30 avril 1991. RÉsultats: La plupart des femmes (94\%) ont subi un dépistage avant l'accouchement et 5,2 \% après l'accouchement. Le statut du dépistage n'a pu être déterminé pour 0,8\% d'entre elles. Un quart de tous les résultats des dépistages postnataux n'ont été disponibles que 48 heures ou plus après l'accouchement. Aucun nourrisson né d'une femme ayant subi un dépistage postnatal ou d'une femme dont le statut de dépistage était inconnu n'a été immunisé pendant la grossesse. La séroprévalence maternelle a été de $1,08 \%$ (95\% d'intervalle de fiabilité, de 0,6, 1,4). Les 22 nourrissons nés de mères HBsAg séropositives avaient reçu une immunoglobuline de l'hépatite B dans les 12 heures de l'accouchement et la première dose de vaccin contre l'hépatite B dans les 24 heures. Le suivi des nourrissons a révélé que seulement $50 \%$ avaient reçu la deuxième et la troisième doses selon le protocole recommandé, $83 \%$ ayant complété les séries d'immunisation. Conclusion: Ces résultats indiquent qu'un programme de dépistage prénatal de HBsAg et une prophylaxie néonatale contre l'hépatite B peuvent être instaurés avec succès dans un hôpital obstétrical de fort volume et qu'une meilleure surveillance des nourrissons est nécessaire pour assurer une vaccination complète.
\end{abstract}

McGill University Faculty of Medicine; Department of Epidemiology and Biostatistics, McGill University and Division of Clinical Epidemiology. Montreal General Hospital; Infectious Disease and Microbiology. St Mary's Hospital; Department of Obstetrics and Gynaecology. St Mary's Hospital; and Research Unit, Jewish General Hospital, Department of Family Medicine, McGill University. Montreal, Quebec

Correspondence and reprints: Dr TW Gyorkos, Division of Clinical Epidemiology, Montreal General Hospital, 1650 Cedar Avenue, Montreal, Quebec H3G 1A4. Telephone (514) 937-6011 ext 4721, Fax (514) 934-8293

Received for publication September 21, 1992. Accepted February 2, 1993 
$\mathrm{O}$ NE OF THE MOST EFFICIENT MECHANISMS OF TRANSMISsion of hepatitis B is vertical transmission from mother to child, primarily at birth. The risk of hepatitis $\mathrm{B}$ infection in infants born to infected mothers ranges from 10 to $85 \%$, depending upon the hepatitis B e antigen (HBeAg) status of the mother (1). Up to $90 \%$ of infected babies become chronic carriers with a personal lifetime mortality risk of approximately $25 \%$ for hepatocellular carcinoma or cirrhosis (2). Over $90 \%$ of perinatal infections can be prevented if infants born to hepatitis B surface antigen (HBsAg)-positive mothers are given hepatitis B immunoglobulin (HBIG) and initiation of the hepatitis B vaccine series shortly after birth (3-4). Timing is critical as no additional efficacy beyond that of the vaccine alone is achieved when HBIG is given more than $48 \mathrm{~h}$ after delivery (5-6). Vaccine efficacy is also diminished if there are lengthy delays between scheduled vaccine doses.

Since 1989, the National Advisory Committee on Immunization (NACI) has recommended screening of all pregnant women for HBsAg. This approach replaced the previous selective screening strategy, which was based on the presence of high risk factors (7). This change was based on the finding that as many as 50\% of all HBsAg-positive women have no known risk factors for hepatitis B infection (8-12).

The present study was undertaken at St Mary's Hospital, Montreal, to evaluate the extent to which current recommendations related to prevention of perinatal transmission of hepatitis $\mathrm{B}$ are being implemented. This hospital has the second largest number of deliveries in the Montreal area (over 4000 per year) and a department of obstetrics policy of HBsAg screening of all pregnant women. Specifically, this policy means that all women giving birth at St Mary's should be screened for HBsAg, ideally at the hospital laboratory. In practice, at the time of this study, physicians delivering at the hospital were expected to request that a hepatitis B screening test be performed on each prenatal serum.

The objectives of the study were to determine the following: the proportion of women delivering during a recent six-month period who were screened prenatally for HBsAg; the prevalence of HBsAg among screened women; and the extent to which infants of HBsAg-positive mothers received the appropriate regimen of immunizations.

\section{METHODS}

The study protocol was reviewed and approved by the St Mary's Hospital Research Ethics Committee, after which a list of all deliveries between November 1, 1990 and April 30, 1991 was obtained. The names from this list were sought in the hospital virology laboratory card file in order to determine screening and HBsAg status. Those names not shown by the card file to have been screened were followed up by comparing with the virology prenatal screening logbook, the blood bank card file and by chart review (hospital and office charts). An HBsAg result in either the virology laboratory or the hospital chart was evidence that a screening test had been performed. The status of women indicated by the card file to be HBsAg-positive was double-checked with the virology hepatitis B logbook and by chart review. Screening date was available from the virology laboratory while this information was not always available from the patients' hospital charts. No other hepatitis B serological tests were searched for.

Hepatitis B screening was performed using an enzyme-linked immunoadsorbent assay (ELISA) test kit on a bi-weekly basis in the hospital laboratory.

Postnatal administration of HBIG and the first dose of hepatitis B vaccine to infants born to HBsAg-positive mothers was ascertained from the neonatal logbook, which is kept in the nursery to document hepatitis B immunization, and followed up with chart review. The HBsAg-positive mothers were then contacted by telephone to obtain the dates of the second and third doses of vaccine to their infants. This information was available from the child's Carnet de Santé (in possession of the parents), which includes an official record of immunization.

\section{RESULTS}

A total of 2054 women delivered during the study period. Seven were excluded on the basis of stillbirth (all were HBsAg-negative). Twins were counted as one event with respect to screening and seroprevalence.

An HBsAg screening result was found in hospital records for 2030 (99.2\%) of the mothers delivering live births (Table 1). Of these, 1924 (94\%) had been tested prenatally. Nine women had an indication of being HBsAg-negative only in the hospital chart without any recorded screening date and were included in the number screened prenatally.

For 106 women (5.2\%), test results were not available until the actual day of delivery or thereafter. These women were classified as having been screened postnatally. Results of screening were available on the day of delivery for 18 women, day 1 postpartum for 52 women, day 2 for 17 women and day 3 for nine women. None of the infants whose mothers were screened postnatally received expectant immunization.

Seventeen women $(0.8 \%)$ had an unknown screening status according to hospital records. The virology laboratory had received postnatal blood samples for 13 of these women but an HBsAg screening test had not been requested. Only two women of unknown screening status had not received prenatal care. The physicians of all 17 women were contacted and it was found that three women had documentation in their office charts indicating that they were screened and were HBsAgnegative. It is not clear whether these results were made available to hospital personnel at the time of delivery and therefore these women were not counted 


\section{TABLE 1}

Hepatitis B surface antigen (HBsAg) screening status of 2047 women delivering between November 1, 1990 and April 30, 1991, at St Mary's Hospital, Montreal, by timing of screening test

\begin{tabular}{lccccr}
\hline Timing of & \multicolumn{4}{c}{ HBsAg status } & \\
screening test & Negative & Positive & Unknown & Total \\
\hline Prenatal & 1902 & 22 & - & 1924 \\
Postnatal & 106 & - & - & 106 \\
Unknown & - & - & 17 & 17 \\
Total & 2008 & 22 & 17 & 2047 \\
Percentage & 98.1 & 1.1 & 0.8 & 100 \\
\hline
\end{tabular}

TABLE 2

Immunization status of infants born to hepatitis B surface antigen (HBsAg)-positive mothers: second and third doses of hepatitis B vaccine*

\begin{tabular}{lcccc}
\hline Second dose (age in & \multicolumn{5}{c}{ Third dose (months after second dose) } \\
months when given) & $5-6$ & $7-8$ & Not given & Total \\
\hline 1 & 10 & 1 & & 11 \\
2 & 1 & 1 & 1 & 3 \\
3 & & 1 & & 1 \\
$4-5$ & & & $1^{\dagger}$ & 1 \\
6 & 1 & & 1 & 2 \\
7 & & & & 1 \\
$8-11$ & & & 1 & 1 \\
12 & & & 1 & 1 \\
Not given & 12 & 3 & $5^{\dagger}$ & 20 \\
Total &
\end{tabular}

"Only 20 infants were followed up with respect to the second and third doses of hepatitis B vaccine because one infant died shortly after birth of congenital toxoplasmosis and another was lost to follow-up. Those included in shaded portion ultimately completed the immunization series. ${ }^{\dagger}$ Case of clinical hepatitis $G$; ${ }^{\dagger}$ Please see text for explanation

as having a known screening status at delivery. None of the infants born to this group of women were immunized before discharge.

The HBsAg seroprevalence was $1.08 \%$ (22 of 2030) (95\% confidence interval from 0.6 to 1.4 ) in this population (Table 1). All 22 children received HBIG within $12 \mathrm{~h}$ of delivery. Twelve children also received their first dose of vaccine within $12 \mathrm{~h}$ and the remainder within $24 \mathrm{~h}$.

Table 2 displays the data on the administration of the second and third doses of hepatitis B vaccine. Only 11 of the 20 infants for whom follow-up was possible received both doses according to recommendations. Of the five children who did not complete the immunization series at follow-up, one received neither the second nor the third dose. One of the infants who received the second dose at six months developed a clinical hepatitis $\mathrm{B}$ infection confirmed by serology (developed approximately four months later). One child had still not received the third dose 12 months after having received the second. The remaining two children received the second dose within five months before this study (one at seven months of age and the other at 12). Therefore, the timing of administration of the third dose with respect to the second could not be assessed, and these two infants were excluded from the estimation of the ultimate completion rate, which was 15 of $18(83 \%)$.

\section{DISCUSSION}

Screening: Screening was very successful in that $94 \%$ of women were screened prenatally and another $5.2 \%$ were screened postnatally. Several characteristics of this hospital may have contributed to the high rate of screening. St Mary's Hospital is a teaching hospital and has a departmental policy of universal prenatal HBsAg screening. This has sensitized the staff in the virology laboratory such that the HBsAg screening test is likely to be performed on a prenatal blood sample submitted for other testing, without a specific request for an $\mathrm{HBsAg}$ test.

There are several possible explanations for an unknown screening status $(0.8 \%)$. It is possible that these women were neither screened prenatally nor postnatally. Omission of prenatal screening could have been due to lack of prenatal care (two women), physician failure to order the test, or lack of compliance on the part of the woman. Failure of screening at the time of delivery is more difficult to explain given the hospital policy. It is also possible that the test was carried out at an outside laboratory with loss of results, failure of communication of results to the physician, or failure to record the result in the prenatal chart. Less likely is the possibility that the virology laboratory staff failed to carry out the specified test or to record the result properly. Complete screening was possible given that postnatal samples were available for most of the 17 'unknowns' and urgent screening could have been performed. During the study the virology laboratory was only screening sera for HBsAg when requested, whereas they are now screening all prenatal sera on a routine basis.

One study found that expecting mothers not screened prenatally for HBsAg had a higher risk of being seropositive than those who were screened (13). In the present study, of the 106 women screened postnatally, none were HBsAg-positive. Twenty-six postnatal screening results were not available until $48 \mathrm{~h}$ or longer postdelivery. This could have resulted in an inability to obtain HBsAg testing within adequate time to administer prophylaxis according to recommendations (14). Fortunately, none of these women were seropositive. However, this can be seen as an important potential problem given the reduced efficacy of the prophylactic regimen if given after $48 \mathrm{~h}$. None of the infants born to mothers who were only screened postnatally received expectant immunizations. This issue has not been specifically addressed by NACI (15) and is not in accordance with Centers for Disease Control recommendations (16). Improving prenatal screening would decrease the necessity and cost of administering the expectant immunizations.

Seroprevalence: HBsAg seroprevalence in pregnant 
women at this hospital appears to be much higher than other estimates of seroprevalence reported elsewhere in the Montreal area $(0.34 \%)(17)$, in Alberta $(0.3 \%)(8)$ or in Manitoba (0.61\%) (18). However, these three studies based their estimates of seroprevalence on serum specimens rather than individuals, and are subject to various sources of error. Direct comparisons are not appropriate.

Immunization: The timing of administration of HBIG and the first dose of hepatitis B vaccine was universally appropriate given the recommendations in effect at the time (15). More recently, the United States Immunization Practices Advisory Committee (ACIP) has recommended that the first dose of hepatitis $\mathrm{B}$ vaccine also be given within the first $12 \mathrm{~h}$ (16).

Of the 20 infants followed up, about $50 \%$ received both the second and third doses of hepatitis $\mathrm{B}$ vaccine according to recommendations. The ultimate completion rate for those infants for whom full assessment was possible was $83 \%$. These results are comparable to those found in another study (19).

All babies are required to be seen twice by a pediatrician in the hospital nursery before discharge. This pediatrician may be involved in the infant's care following discharge. In the case of an infant requiring follow-

ACKNOWLEDGEMENTS: The authors thank the staff of the St Mary's Hospital Virology Laboratory, and participating physicians and their staff for their invaluable cooperation and aid in this endeavour. Thanks also to Dr Gilles Delage for his constructive comments on the manuscript.

\section{REFERENCES}

1. Margolis HS, Alter MJ, Hadler SC. Hepatitis B: Evolving epidemiology and implications for control. Semin Liver Dis 1991;11:84-92.

2. Beasley RP, Hwang L-Y. Epidemiology of hepatocellular carcinoma. In: Vyas GN, Dienstag JL, Hoofnagle JH. Viral Hepatitis and Liver Disease. New York: Grune \& Stratton, 1984:209-24.

3. Stevens CE, Toy PT, Tong MJ, et al. Perinatal hepatitis B virus transmission in the United States: Prevention by passive-active immunization. JAMA 1985;253:1740-5.

4. Stevens CE, Taylor PE, Tong MJ, et al. Yeast-recomb- inant hepatitis B vaccine: Efficacy with hepatitis B immune globulin in prevention of perinatal hepatitis B virus transmission. JAMA 1987;257:2612-6.

5. Beasley RP, Stevens CE. Vertical transmission of hepatitis B virus and interruption with globulin. In: Vyas GM, Cohen SN, Schmid R, eds. Viral Hepatitis: A Contemporary Assessment of Etiology, Epidemiology, Pathogenesis, and Prevention. Philadelphia: The Franklin Institute Press, 1978:333-45.

6. Kane MA, Hadler SC, Margolis HS (CDC). In reply to: Ross JW. Prenatal screening for hepatitis B antigen. JAMA 1989;261:1727-8.

7. National Advisory Committee on Immmunization. Canadian immunization guide. Can Dis Wkly Rep 1989;15:85-8.

8. Okun NB, Larke RP, Waters JR, Joffres MR. Success of a program of routine prenatal screening for hepatitis B surface antigen: The first two years. Can Med Assoc J 1990:143:1317-21.

9. Jonas MM, Schiff ER, O'Sullivan MJ, et al. Failure of Centers for Disease Control criteria to identify hepatitis B infection in a large municipal obstetrical population. Ann Intern Med 1987:107:335-7. up immunization, the hospital pediatrician would notify the pediatrician designated by the mother. In addition, the community health department is advised by the hospital of babies requiring immunization for follow-up purposes. Immunizations are typically administered at the local community health clinic but may be administered at the pediatrician's office. The vaccine must be ordered from the community health department. It is unclear at what point the system failed in the cases of incomplete immunizations observed in the present study. More effort needs to be placed on developing a specific mechanism to ensure that infants at high risk are fully immunized.

In August 1991, NACI recommended universal immunization of all infants against hepatitis B (20). ACIP and the Infectious Diseases and Immunization Committee of the Canadian Paediatric Society also recommended universal immunization of newborns $(16,21)$ but, at the same time, reaffirmed the absolute necessity of prenatal screening. The consensus view is that it is only by a combination of universal maternal screening, aggressive immunization and follow-up of infants born to HBsAg-positive mothers, and universal infant immunization that infection with hepatitis $B$ virus can best be prevented.

10. Summers PR, Biswas MK, Pastorek JG, Pernoll ML, Smith LG. The pregnant hepatitis B carrier: Evidence favoring comprehensive antepartum screening. Obstet Gynecol 1987;69:701-4.

11. Butterfield CR, Shockley M, San Miguel G, Rosa C. Routine screening for hepatitis B in an obstetric population. Obstet Gynecol 1990;76:25-7.

12. Greenspoon JS, Martin J, Greenspoon RL, McNamara BT. Necessity for routine obstetric screening for hepatitis B surface antigen. J Reprod Med 1989;34:655-8.

13. Silverman NS, Darby MJ, Ronkin SL, Wapner RJ. Hepatitis B prevalence in an unregistered prenatal population: Implications for neonatal therapy. JAMA 1991;266:2852-5.

14. Ross JW. Prenatal screening for hepatitis B antigen. JAMA 1989;261:1727-8.

15. National Advisory Committee on Immunization. Dixon JM (chairman). Canadian Immunization Guide, 3rd edn. Ottawa: Minister of Supply and Services Canada, 1989:54-5.

16. Centers for Disease Control. Hepatitis B virus: A comprehensive strategy for eliminating transmission in the United States through universal childhood vaccination: Recommendations of the Immunization Practices Advisory Committee (ACIP). MMWR 1991;40:1-19.

17. Delage G, Montplaisir S, Remy-Prince S, Pierri E. Prevalence of hepatitis B virus infection in pregnant women in the Montreal area. Can Med Assoc J 1986;134:897-901.

18. Sekla LH, Hammond G, Stackiw W, Eibisch G, Fast M. Testing pregnant women for hepatitis B surface antigen; A pilot study in Manitoba. Can Dis Wkly Rep 1988;14:137-40.

19. Hepatitis B screening and follow-up vaccination of infants of carrier mothers - Atlanta, 1988 and 1989. MMWR 1990;39:405-7.

20. National Advisory Committee on Immunization. Statement on universal immunization against hepatitis B. Can Dis Wkly Rep 1991;17:165.

21. Infectious Diseases and Immunization Committee, Canadian Paediatrics Society. Hepatitis B in Canada: The case for universal vaccination. Can Med Assoc J 1992;146:25-8. 


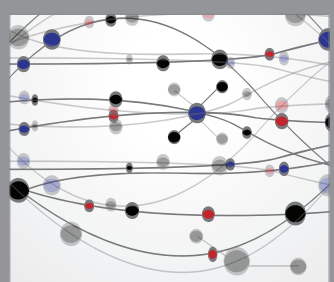

The Scientific World Journal
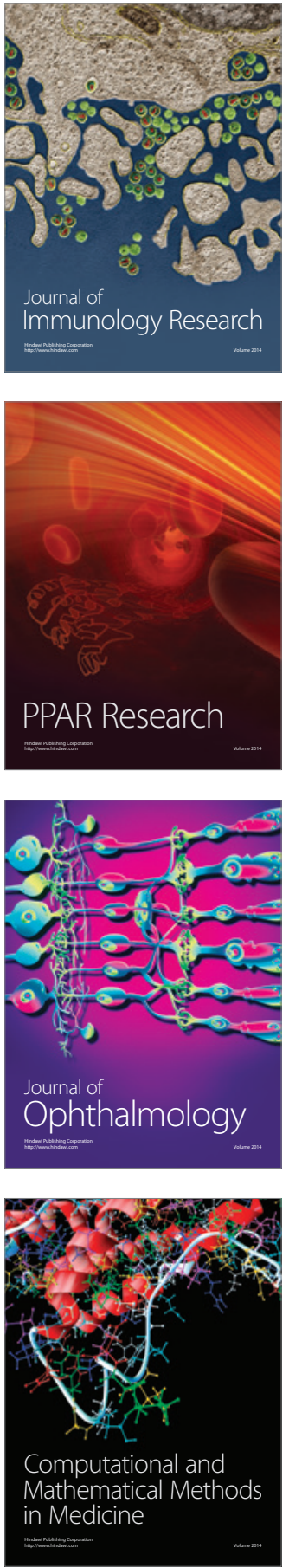

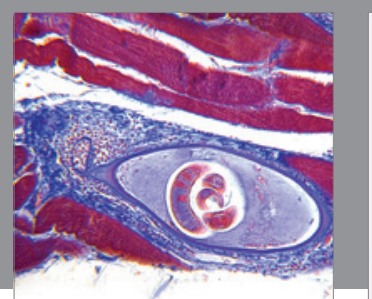

Gastroenterology Research and Practice

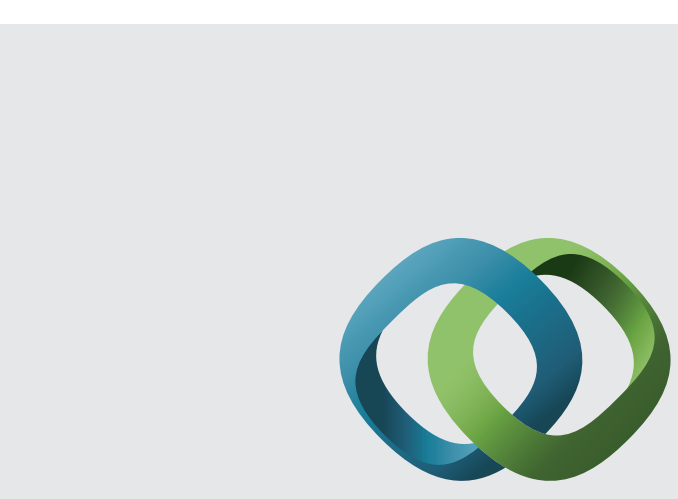

\section{Hindawi}

Submit your manuscripts at

http://www.hindawi.com
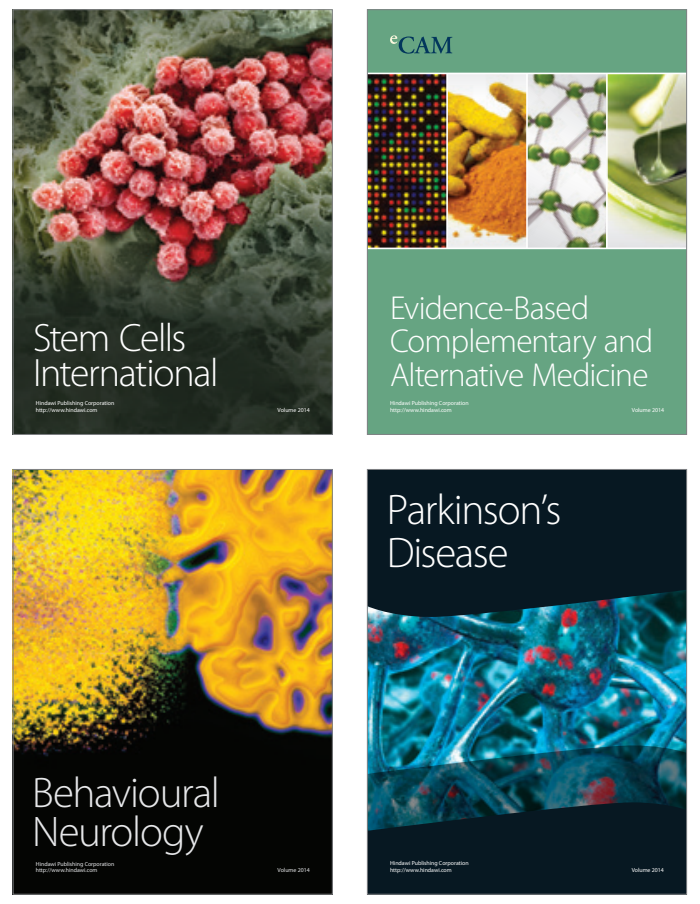
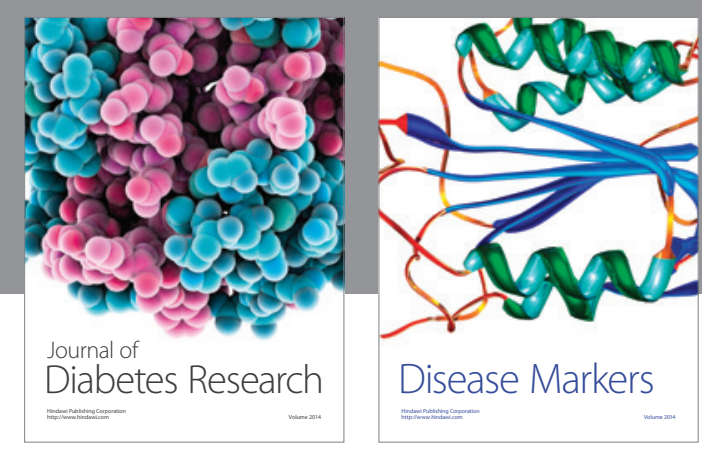

Disease Markers
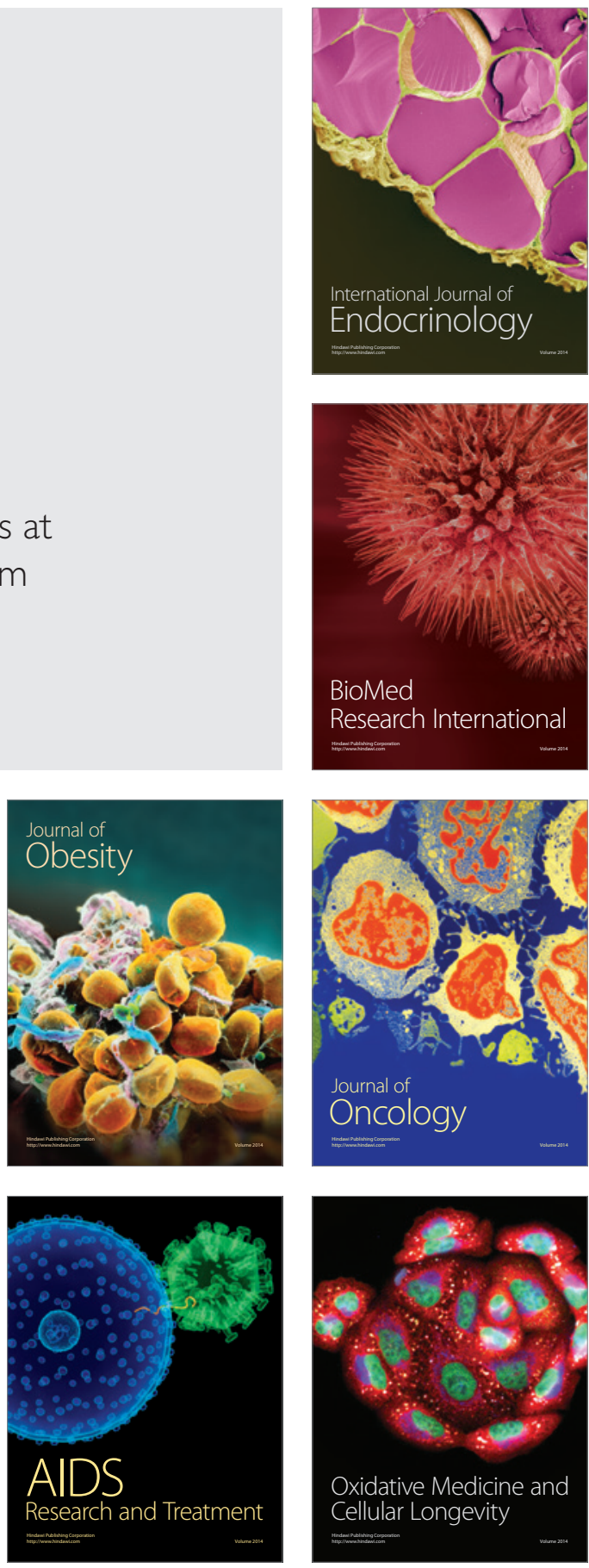